\title{
ASSESSMENT AND SOLUTION OF PROBLEMS OF IMPLEMENTATION OF GOVERNMENT MEDICINE REIMBURSEMENT PROGRAMS IN UKRAINE
}

\author{
Professor Alla Nemchenko, \\ Assistant Professor Viktoriia Nazarkina, \\ Assistant, PhD student YuliiaYe. Kurylenko, \\ Assistant Professor Sergiy V. Himenko
}

Ukraine, Kharkiv, National University of Pharmacy

DOI: https://doi.org/10.31435/rsglobal_ws/31012020/6893

\author{
ARTICLE INFO \\ Received: 27 November 2019 \\ Accepted: 16 January 2020 \\ Published: 31 January 2020

\section{KEYWORDS} \\ Government program, \\ reimbursement, \\ questionnaire of specialists, \\ doctor, \\ pharmacist, \\ patient.
}

\begin{abstract}
The article analyzes the problems of implementation of drug reimbursement programs in Ukraine and in the countries of the world. One of the key problems in the countries of the world is the low index of cooperation between the doctor and the pharmacist, the patient's failure to adhere to the medication regimen and the recommendations of specialists. In Ukraine through questionnaires specialists found that one of the main problems is the unavailability of feedback through the "doctor-pharmacist-patient" and the interaction doctor pharmacist no number of monitoring of medical appointments. The need for close cooperation between doctors, pharmacists, patients and the state in order to justify improving the delivery and receipt of appropriate medical and pharmaceutical care.
\end{abstract}

Citation: Alla Nemchenko, Viktoriia Nazarkina, YuliiaYe. Kurylenko, Sergiy V. Himenko. (2020) Assessment and Solution of Problems of Implementation of Government Medicine Reimbursement Programs in Ukraine. World Science. 1(53), Vol.1. doi: 10.31435/rsglobal_ws/31012020/6893

Copyright: (C) 2020 Alla Nemchenko, Viktoriia Nazarkina, YuliiaYe. Kurylenko, Sergiy V. Himenko. This is an open-access article distributed under the terms of the Creative Commons Attribution License (CC BY). The use, distribution or reproduction in other forums is permitted, provided the original author(s) or licensor are credited and that the original publication in this journal is cited, in accordance with accepted academic practice. No use, distribution or reproduction is permitted which does not comply with these terms.

Introduction. In line with the Global Development Goals of the United Nations General Assembly (UN), one of the acute problems of society is the sound health of the population. Ensuring healthy lifestyles and promoting well-being for the entire population, regardless of gender and age, is an important component of the development of a health system (HS). However, in the current realities of the economic crisis, given the scarce resources of $\mathrm{HE}$, the problem of providing patients with socially important pathologies with accessible medicines (drugs), in particular, cardiovascular diseases (CVD) is becoming more urgent [1].

In this context, Government programs are increasingly gaining publicity regarding the availability of medicines and the prevention of diseases and the promotion of healthy lifestyles that function effectively in developed countries. For example, Canada, Poland, Spain, the Netherlands, Moldova, Greece, Finland, Azerbaijan most often implement reimbursement programs with different levels of co-payment depending on the insurance policy and the disease in the conditions of public health insurance [2,3]. In countries such as the United States, Canada, Brazil, Mexico, Chile, Colombia, and Japan, the Wellness Reimbursement Program - Global, designed to promote and support healthy lifestyles, is widely used for prevention [4,5]. Given the fact that not all patients have an insurance policy in some countries, particularly in the US operating program «Prescription Program is available at all Walmart and Neighborhood Market pharmacies in the United States». With avdyaky program by prescription may receive drugs (for eight groups of diseases) for 4 dollars or 10 dollars depending on the course of treatment (30 or 90 days, respectively) [6]. 
Ukraine has also implemented various reimbursement programs in the process of reforming the health system: a pilot project on state regulation of prices for antihypertensive drugs and insulins [7,8]. From 1/04/2017 Ukraine started in government program «Available medicines» to the composition of which includes the 24 most common treatment INN nosology: cardiovascular disease, type II diabetes and asthma. The purpose of the program is to provide patients with affordable, effective and prevent their premature death $[9,10,11]$.

Because the common opinion of medical and pharmaceutical professionals is becoming more relevant in the process of providing appropriate assistance to patients and participation in reimbursement programs, a number of studies have been conducted to improve the above issues. Thus, in a study called «Pharmacist and physician views on collaborative practice», scientists concluded that collaborative practice could lead to improved patient outcomes and optimized compensation payments [16]. The authors of the article «Facilitating collaboration between pharmacists and physicians using an iterative interview process» ound that cooperation in medical and pharmaceutical care, including monitoring and adherence to the medication regimen, common practice agreements, to resolve issues related to service and compensation, and the mechanism of urgent communication [17]. In this paper, «Exploring successful community pharmacist-physician collaborative working relationships using mixed methods» using the Index of cooperation between the pharmacist and doctor (Physician - Pharmacist Collaborative Index -PPCI) found that professional exchange of ideas between experts and engagement positively affects the development of health and pharmaceutical services to the public [18]. Research «Physician beliefs and attitudes toward collaboration with community pharmacists» group of scientists led by questioning medical and pharmaceutical workers using mailbox confirms that the strategy of cooperation between experts would achieve improvements in the regimen of drugs [19]. In general, all the surveys conducted in the context of the survey confirm that cooperation and consistency of opinion between doctors and pharmacists will help to optimize the process of patient care.

However, there are a number of unresolved problems faced by the healthcare institutions of Ukraine in the process of implementing government programs, which are to actualize the evaluation of healthcare technologies (HTA) as part of pharmaceutical support for CVD patients. It should be noted that the provision of adequate quality medical and pharmaceutical assistance to the population in the countries of the world is realized through regular assessment of all services provided to the population and the creation of feedbacks at various levels.

Based on the above, the purpose of the article is to evaluate the problems faced by medical and pharmaceutical professionals in the implementation of Government programs, as well as to identify ways to address them, in the context of reforming the national health care system in Ukraine.

Materials and Methods. The study used materials from a survey of medical and pharmaceutical specialists conducted by the National University of Pharmacy (NuPH) together with the Department of Health of Kharkiv Regional State Administration and the State Drugs and Drug Control Service in Kharkiv region [12,13]. Information from the official website of the Ministry of Health of Ukraine and the National Health Service of Ukraine $[14,15]$. Methods were chosen logical, statistical, questioning and generalization of information.

Results. In the first phase of the study, an algorithm was proposed to identify the problems faced by medical and pharmaceutical workers in the implementation of their Governments, which includes the following steps. Developed a questionnaire for medical and pharmaceutical workers contained a 17 and 20 questions respectively, while also duplicated in 9 Questions questionnaires to assess the consistency of opinions of experts. The questionnaire of doctors and pharmacists was conducted in the regions and regions of Ukraine, in particular, Kharkiv and Kharkiv region. The calculation of indicators for Kharkiv and the region was carried out separately and compared with other regions of Ukraine since the Kharkiv region was chosen by us for testing and processing of questionnaires. In total, 892 specialists, 445 doctors and 447 pharmaceutical workers participated in the survey.

The problems associated with the implementation of Government programs cannot be objectively assessed without the agreement of the opinions of medical and pharmaceutical workers directly involved in the provision of CVD patients with affordable medicines. That is why, in the second stage of the study, we performed a comparative characterization of the opinions of doctors and pharmacists based on our research.

In the analysis of respondents by articles was established, which among medical and pharmaceutical employees predominate experts female sex. Thus, among doctors of Kharkiv region 
and Kharkiv $61.92 \%$ of respondents, among other regions $79.20 \%$ of specialists and among pharmacists $89.74 \%$ and $89.20 \%$ respectively.

Distribution of experts by age established, that the greatest percentage weight of medical staff in the Kharkiv region and the city. Kharkov were in the age category of 45- 55 years $37.21 \%$, among the medical staff to other areas of the country's largest number was in the range of $60.40 \%$ Specialist.

Among pharmaceutical workers, as in the Kharkiv region and the city. Kharkiv and in other areas of the country a large majority of experts was in the age of $25-35$ years $53.42 \%$ and $57.75 \%$ of respondents. Analysis of factors experience of work on specialty, allowed to set, that length of from 10 to 20 years was in the majority of medical workers in Kharkiv region and the city Kharkiv $36.63 \%$ of respondents, among other medical areas of the country had the largest number length from 5 to 10 years $-77.23 \%$ of specialists. Among the pharmaceutical workers taking part in the survey, both in Kharkiv and Kharkiv and in other regions of the country, the respondent's length of service was from 5 to 10 years $49.57 \%$ and $53.52 \%$ of specialists.

The results of the study showed that pharmaceutical and medical professionals, both in Kharkiv and Kharkiv, as well as in other regions of Ukraine, believe that prescription drug delivery provides safer and more rational pharmacotherapy as opposed to over-the-counter $93.90 \%, 92.08 \%$, $76.07 \%$ and $83.43 \%$ (Fig. 1).
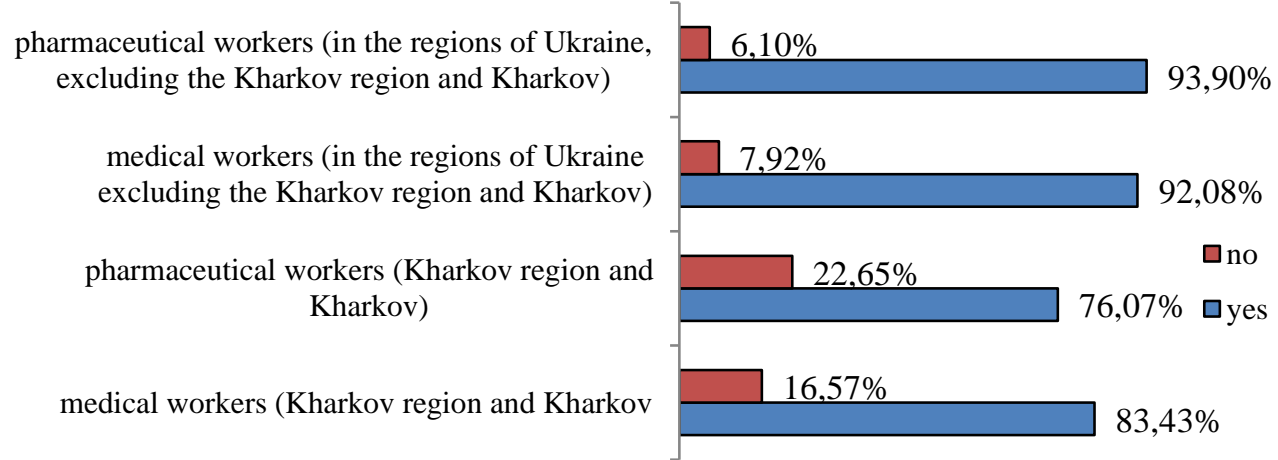

Fig. 1. Analysis of respondents answers regarding safe and rational pharmacotherapy for prescription

It was also found that most medical and pharmaceutical specialists consider that prescribing for INN and dispensing in drugstores under trade names is appropriate and justified from $71.27 \%$ to $94.06 \%$ respectively (Fig. 2).

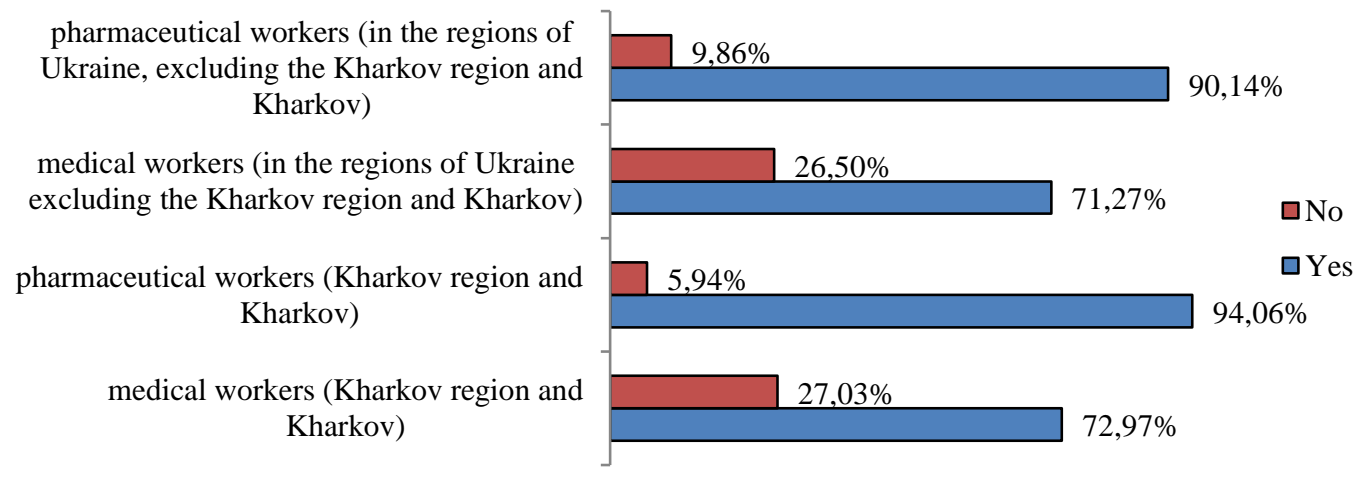

Fig. 2. Answers to the questions about the expediency of the dispensation of drugs

Interesting and unpredictable are the experts' answers to the questions regarding the methods of evaluation of prescription medicines that need to be implemented in Ukraine (up to three options could be selected). It was found that most medical and pharmaceutical workers, both from Kharkiv and other regions of the country, believe that guidelines and standards for prescription leave should be introduced $81.89 \%, 61.11 \%, 80.20 \%, 77.64 \%$ respondents, the smallest number of experts believe that the use of financial motivation of doctors for the proper prescription will help if it is introduced $39.24 \%, 26.07 \%, 22.77 \%, 15.96$ respondents respectively. 
Only $59.01 \%$ and $62.68 \%$ of medical and pharmaceutical specialists from Kharkiv region and $56.41 \%$ and $52.68 \%$ of respondents from other regions of the country support the implementation of monitoring of prescribing by doctors. Although medical prescribing monitoring would provide and outline more objective problems, the trends and conditions that, not only the physician and patient will face in the future, but also the general health system.

Our analysis of the data on appointments and vacations for patients with CVD in the Ministry of Emergencies with in the program «Available medicines» revealed that doctors in Kharkiv and other regions of the country appoint, and pharmacists most often: Enalapril, in the second position of Amlodipine, in the third step for a hundred appointments Clopidogrel. Drugs are most often found in pharmacotherapy regimens in accordance with clinical protocols for the provision of medical care to patients in the specialty «Cardiology» (Fig.3).

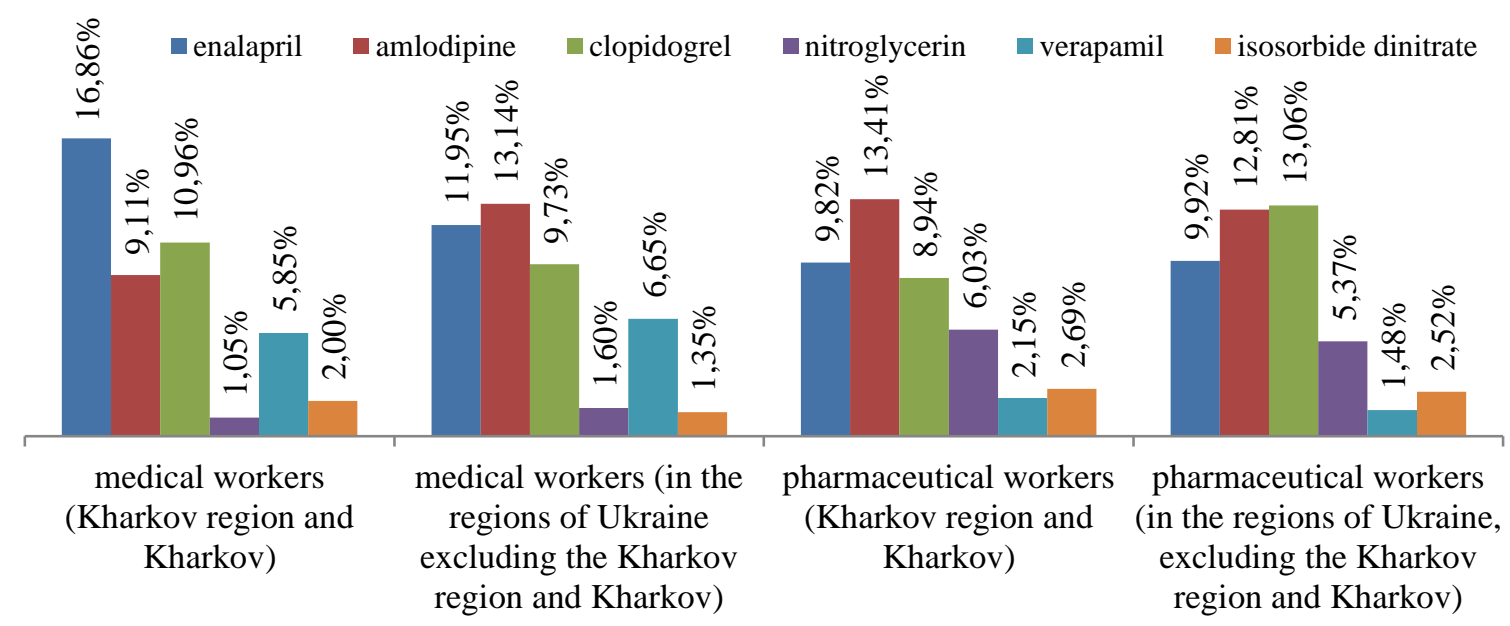

\section{Fig.3. Results of appointments and vacations for patients with CVD under the Available medicines program (fragment)}

Nitroglycerin, Verapamil and Isosorbide dinitrate were also found to be significantly less likely to be administered and released. The study found that Amiodarone, Hydrochlorothiazide drugs are sold by pharmacy establishments in less quantity than prescribed by a doctor. We believe that this is due to the fact that CVD patients simply do not go to the pharmacy with a prescription. However, on the contrary, drugs such as Spironolactone, Furosemide are sold by pharmacies more than prescribed by doctors. This fact is due to the fact that most patients do not go to the hospital with the advice of a doctor and do not receive a prescription, and engage in self-medication, which can not only harm the health of the patient, but also lead to a fatal case in case of incorrect or improper administration of drugs.

Therefore, our next issue was related to awareness-raising activities to warn patients about selfmedication, including on television, radio, and the Internet and social networks. Answers to questions about experts warning patients against self-medication, showed that $79.65 \%$ and $93.07 \%$ of physicians from Kharkov raids hone and other areas of the country $76.07 \%$ and $96.71 \%$ to subjected chayut it is necessary. Therefore, the authorities should pay more attention to restricting or even banning the promotion of medicines, on the one hand, on all the above-mentioned information resources, and on the other, increasing measures to promote healthy lifestyles and warnings against self-medication.

According to a survey, it has also been found that the proliferation of computer information systems (CIS) is gaining momentum in the HS. By distributing CIS were $82.56 \%$ physician and $79.59 \%$ headlights matsevtiv of Kharkiv and $84.16 \%$ of physicians and $94.37 \%$ a pharmacist and other regions of Ukraine and against were $17.44 \%$ and $25.11 \%$ specialists and $15.84 \%$ and $5.63 \%$ of respondents, respectively (Fig. 4).

Analysis of the answers to the questions regarding the introduction of electronic prescription and electronic medical cards in the system of HS showed that $77.33 \%$ and $89.11 \%$ of medical specialists from Kharkiv region and other regions of the country and $71.37 \%$ and $91.08 \%$ are considered to be relevant of pharmaceutical workers respectively. However, the introduction of electronic medical records and electronic recipe voted $28.63 \%$ and $8.92 \%$ pharmaceutical's employees and $22.67 \%$ and $10.89 \%$ medical industry respectively. According to the results of the survey, fears of medical and pharmaceutical workers regarding the introduction of electronic formulations and 
electronic medical cards are related to the age of the working workers and their inability to work with operating systems, and introduction of specialist training is possible only with the support of the state.

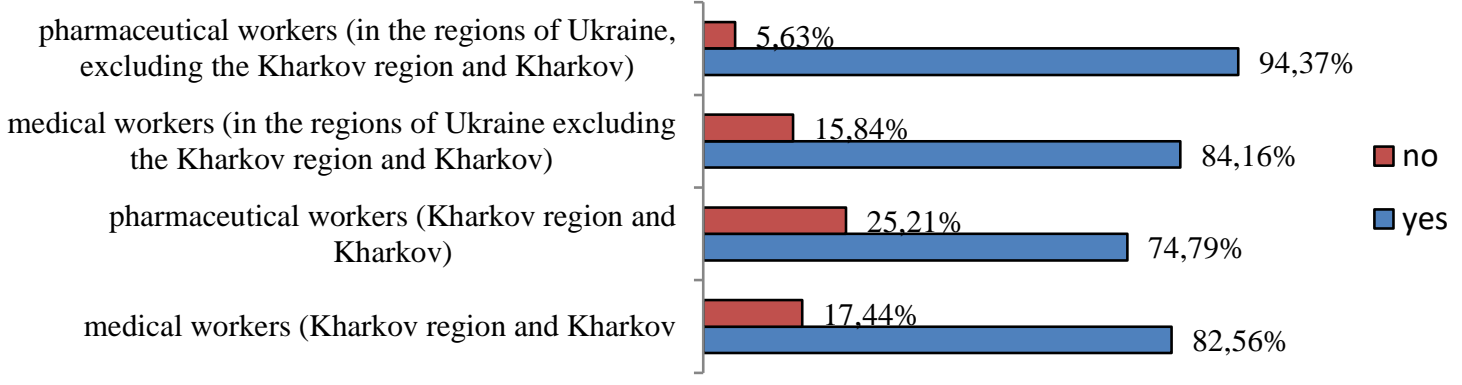

\section{Fig. 4. Structure of experts responses to the dissemination of computer information systems in the HS}

Due to the successful international experience in the distribution of electronic mobile applications in Ukraine, it will minimize the problems in the health care system that physicians and pharmacists most often encounter when implementing Government programs to provide patients with affordable medicines. According to doctors and pharmacists from Kharkiv and other regions of the country, it is advisable to develop and implement in the national healthcare electronic form and clinical guidelines (in the form of a mobile supplement), $74.42 \%$ and $85.15 \%$ and $75.21 \%$ and $90.14 \%$ respectively. One of the priority problems faced by both medical and pharmaceutical professionals is the low efficiency of feedback between the physician, patient and pharmacist (Fig.5).

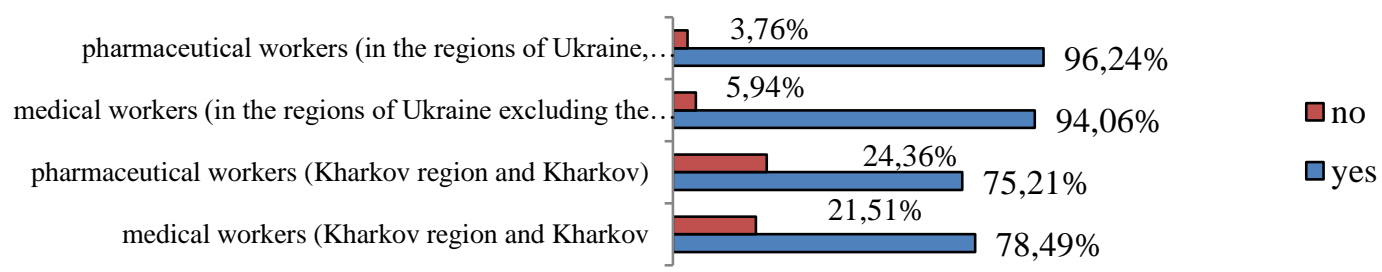

\section{Fig. 5. Structure of respondents response to the need for feedback in the doctor-pharmacist system}

That is why at each of the stages of providing pharmaceutical assistance, feedback is needed in the «doctor-patient-pharmacist» system, which cannot be done without developing specialized information products and adapting them to the field of health care.

Thus, according to $75.21 \%$ of pharmacists from Kharkiv region and $96.24 \%$ from other regions of the country and doctors $-78.49 \%$ and $94.06 \%$ require the development of special software products to provide feedback in the system (doctor - pharmacist patient).

At the final stage of the research summarizing the results of the questionnaire, it can be noted that it is necessary to:

- Adjustment and regulation of feedback in the systems of doctor-patient-pharmacist and state-PPE pharmacy in the HTA system. Establishing these links will help States and all entities participating in Government programs to provide patients with CVD with affordable medicines to remove obstacles that impede the effective functioning of the programs;

- implementation of guidelines and standards for prescription drug delivery;

- monitoring of medical prescriptions;

- active use of CIS in the HE system.

\section{Conclusions.}

1. Improvement of the system of providing the basic drugs to the population of countries of the world suffering from socially important pathologies, regardless of social status and income level, is a priority direction in the development of the field of health care. Therefore, leading countries in the world and developing countries are actively implementing the program of reimbursement of drugs.

2. Reform of health care is currently an urgent and necessary step in the development of health care and pharmaceutical support for the Ukrainian population. At the present stage, there is no socially effective policy for the development of the national system of health care, first of all in the process of implementation of Government programs on pharmaceutical provision of accessible medicines for patients with socially important pathologies, in particular CVD. 
3. It is established that the vast majority of pharmaceutical and medical professionals, both in Kharkiv region and in other regions of Ukraine, consider that prescription drug delivery provides safer and more rational pharmacotherapy as opposed to non-prescription medication 93.90\%, 92.08\%, $76.07 \%$ and $83.43 \%$. According to the survey $77.03 \%$ of respondents from Kharkiv region and $83.17 \%$ of respondents from other regions of Ukraine consider that it is necessary to monitor medical prescriptions.

4. According to the results of a questionnaire survey of health care professionals on appointments and leave of patients with CVD in the Ministry of Emergencies within the program «Aviable Medicines» revealed that doctors prescribe Kharkiv and other regions of the country, and dispensers - Enalapril (16.86\%) and $97(11.95 \%)$ physicians and $(9.82 \%)$ and $(9.92 \%)$ pharmacists, in the second position; Amlodipine $(9.11 \%)$ and $(13.14 \%)$ medical professionals and $(13.41 \%)$ and $(12.81 \%)$ pharmacists, in the third place by frequency of prescriptions Clopidogrel $(10.96 \%)$ and $(9.73 \%)$ medical specialists and $(8.94 \%)$ and $(13.06 \%)$ pharmacist.

5. According to the results of the research it was found that it is expedient to introduce electronic medical cards and electronic formulations, disseminate CIS in the medical system, monitor medical prescriptions, electronic forms and clinical guidelines (in the form of a mobile application), as well as establish feedback in the system «doctor-patient-pharmacist».

\section{REFERENCES}

1. Goals to Trans form Our World. Available at: https://www.un.org/sustainabilityevelopment/health/

2. Wellness reimbursement program - global. Available at: file:///C:/Users/t/Downloads/Global-WellnessReimbursement-Program-122118.pdf

3. Reimbursement Issues Cited as Central Challenge in Physician Salary Survey. Available at: https://www.pharmacytimes.com/resource-centers/reimbursement/reimbursement-issues-cited-as-central-challengein-physician-salary-survey

4. Pharmaceutical pricing and reimbursement policies in Canada. Available at: https://www.oecd.org/canada/37868186.pdf

5. Medicines reimbursement policies and Europe. Available at: http://www.euro.who.int/_data/assets/pdf_file/0011/376625/pharmaceutical-reimbursement-eng.pdf?ua=1

6. The Prescription Program ("Walmart Retail Pharmacies"). Available at: https://www.walmart.com/cp/\$4prescriptions/1078664

7. The Cabinet of Ministers of Ukraine Transformation of Health Care. What has changed? Available at: https://www.kmu.gov.ua/en/news/transformaciya-ohoroni-zdorovya-shcho-zminilosya

8. Pilot project on state regulation of prices. Available at: http://www.dec.gov.ua/index.php/ua/novini-tapodiji/2-uncategorised/7-pilotnij-proekt-shchodo-derzhavnogo-regulyuvannya-tsin

9. Some questions about the cost of recovery of insulin drugs. Available at: https://www.kmu.gov.ua/ua/npas/248939410

10. Some issues of reimbursement of medicines. Available at: https:/law.work.gov.ua/laws/show/135-2019-\%D0\%BF

11. Available medicines. Available at: http://liky.gov.ua/

12. Department of Health of Kharkiv Regional State Administration. Available at: https://kharkivoda.gov.ua/oblasna-state-administratsiya/structure-administratsiyi/structural-pidrozdili/141

13. State Service for Drugs and Drug Control in Kharkiv Oblast. Available at: http://dls.gov.ua/\%D1\%85\%D0\%B0\%D1\%80\%D0\%BA\%D1\%96\%D0\%B2\%D1\%81\%D1\%8C\%D0\%BA $\% \mathrm{D} 0 \% \mathrm{~B} 0-\% \mathrm{D} 0 \% \mathrm{BE} \% \mathrm{D} 0 \% \mathrm{~B} 1 \% \mathrm{D} 0 \% \mathrm{BB} \% \mathrm{D} 0 \% \mathrm{~B} 0 \% \mathrm{D} 1 \% 81 \% \mathrm{D} 1 \% 82 \% \mathrm{D} 1 \% 8 \mathrm{C} /$

14. Ministry of Health of Ukraine. Available at: http://moz.gov.ua/plan-reform

15. National Health Service of Ukraine. Available at: https://nszu.gov.ua/

16. Kelly DV, Bishop L, Young S, Hawboldt J, Phillips L, Keough TM. Pharmacist and physician views on collaborative practice: Findings from the community pharmaceutical care project. Can Pharm J (Ott). 2013; 146 (4) P. 218-226. doi: $10.1177 / 1715163513492642$

17. Chui, MA, Stone, JA, Odukoya, OK, \& Maxwell, L. (2014). Facilitating collaboration between pharmacists and physicians using an iterative interview process. Journal of the American Pharmacists Association: JAPhA, 54 (1), 35-41. doi: 10.1331/JAPhA.2014.13104

18. Snyder, ME, Zillich, AJ, Primack, BA, Rice, KR, Somma McGivney, MA, Pringle, JL, \& Smith, RB (2010). Exploring successful community pharmacist-physician collaborative working relationships using mixed methods. Research in social \& administra tive pharmacy: RSAP, 6(4). P. 307-323. doi: 10.1016/j.sapharm.2009.11.008

19. Suzan Kucukarslan, Steven Lai, Yannan Dong, Noor Al-Bassam, Karen Kim (2011). 